\title{
Scheduling Maintenance of Cooling System based on Risk Priority Number (RPN) using Adaptive Neural Network
}

\author{
Bustani, Rusdiansyah, Mohammad Zainuddin, Supriadi
}

\begin{abstract}
Power outages caused by factors outside the established policy will have an impact on the decline in electricity supply services and other cost related impacts. The reliability of the power plant feeder, in this case, is very important to monitor and maintain. The performance of power plant feeder can be reviewed based on the variable duration of power outage and power which fails to distribute. In this study, $1^{\text {st }}$ order FTS (Fuzzy Time Series) is used to predict the feeder's performance through the predictive activity of both those variables in the actual year and the following year. The prediction results state that in 2017 there was a $20.54 \%$ decrease in performance.
\end{abstract}

Keywords - feeder, power outages, undistributed power, $1^{\text {st }}$ order FTS.

\section{INTRODUCTION}

The use of equipment in a continuous unit / production system will result in lower availability of a unit/system. Without planned maintenance actions will result in a decline in reliability (reliability). Reliability can be maintained by performing good and regular maintenance scheduling. Ideally, maintenance is done to keep equipment and systems running efficiently at least for component lifetime [1] . Maintenance is the activity of keeping the unit / system in order to remain consistent in operation. Maintenance activities should be accurate, consistent and planned. The need for maintenance is based on actual failure or what will happen. Type of functional failure varies, one of which is the occurrence of shut down. Several studies on various maintenance systems have been performed, such as Preventive Maintenance (PM) [2, 3], Breakdown Maintenance, Scheduled Maintenance, Total Productive Maintenance (TPM), Reliability-Centered Maintenance (RCM) [4], Predictive (Conditional Based) Maintenance (CBM) [5-7], distributed Re-entrant Flow-shop scheduling (DRFS) []].

The main variables in maintenance are failure or functional failure. Failure is a condition that does not meet desired or intended goals, and can be viewed as the opposite of success. Failure is also interpreted as an error that can be known or seen clearly (observable) by the user, while the

Revised Manuscript Received on September 10, 2019.

Bustani, Department of Electrical Engineering, State Polytechnic of Samarinda, East Kalimantan, Indonesia.

(E-mail: bustani27@gmail.com)

Rusdiansyah, Department of Electrical Engineering, State Polytechnic of Samarinda, East Kalimantan, Indonesia.

(E-mail: rusdiansyah_2010@yahoo.co.id)

Mohammad Zainuddin, Department of Information Technology, State Polytechnic of Samarinda, East Kalimantan, Indonesia.

(E-mail: zainuddin011062@gmail.com)

Supriadi, Department of Information Technology, State Polytechnic of Samarinda, East Kalimantan, Indonesia.

(E-mail: supriadi.polnes@gmail.com) fault is more internal. A fault tolerant system must be able to detect the fault that occurs and perform certain actions so that the fault does not turn into failure. Failure analysis is a discipline that is widely used in various manufacturing industries. Failure analysis is the process of collecting and analyzing data to determine the cause of failure, often with the goal of determining corrective action or accountability. The failure analysis process depends on the collection of equipment data that fails for further examination, then performs the analysis with various methods. Several methods that have been studied are FMEA (Failure Mode and Effects Analysis) [ㅇ, 10], Fuzzy-based FMEA [1, 12], Generalized Evidential FMEA [13].

If the failure can be predicted properly then maintenance can be planned well too. Predicted failure is usually very useful for the application of PM or CBM. Several studies have been conducted related to the prediction of failure that focuses more on how a method is applied, among them the Kalman Filter method [14], Angle-based Subspace Anomaly

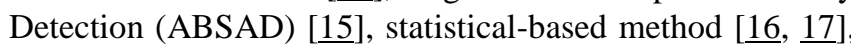
machine learning based [18].

ANN (Artificial Neural Network) is one of AI (Artificial Intelligent) concept which applies machine learning method in its learning process. In this study, ANN-BP (Back Propagation) was used to predict the failure of cooling system based on RPN (Risk Priority Number). Adaptive learning is applied to improve the performance of ANN-BP. The aim of this study is to schedule maintenance of cooling systems based on predicted RPN results.

\section{II.METHODS}

\subsection{Failure Mode and Effects Analysis (FMEA)}

FMEA is a method that systematically identifies the impact or consequences of system failure and reduces or eliminates the chances of failure. FMEA is a qualitative method of analysis. FMEA contains failure modes, the cause of how a component can encounter failure of operation/damage. Analysis starts from functional failure for each functional subsystem. Components included in the analysis are the components/machines that have the potential to cause a functional failure of the previous repair records.

Identification of operating unit components is required to know: type, function, failure, failure mode and failure effect of each component. The results of identification that have been done will be used as the basis for determining the

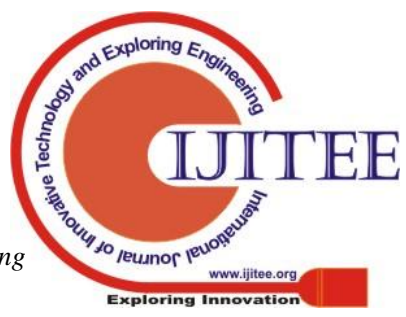


criteria of failure mode evaluation.

\subsubsection{Determination of Qualification and Weight of Each} Evaluation Parameter.

The parameters of failure evaluation are expressed in the RPN (Risk Priority Number) index:

$$
R P N=S \times O \quad(1)
$$

Where $S$ (Severity) is the potential impact of failure, $O$ (Occurrence) is the number of failures that occur. Tables 1 and 2 show the weight of each evaluation parameter.

Table 1. Occurrence

\begin{tabular}{cc}
\hline Score & Description (period 18 months) \\
\hline 1 & 2 failure for a month \\
2 & 3 failures for a month \\
3 & 4 failures for a month \\
4 & 5 failures for a month \\
5 & 6 failures for a month \\
6 & 7 failures for a month \\
7 & 8 failures for a month \\
\hline
\end{tabular}

As an object of this study is the operating unit of Cooling System in Utility Unit Kaltim-2 East Kalimantan Fertilizer Co. Ltd. - Indonesia. The result of component identification in this unit is shown in Table 3 . The result of weighting failure mode based on the failure effect is shown in Table 4.

Table 2. Severity

\begin{tabular}{|c|c|c|}
\hline Score & Qualification & Description \\
\hline 1 & $\begin{array}{l}\text { Very } \\
\text { insignificant } \\
\text { effect }\end{array}$ & $\begin{array}{l}\text { Can be handled immediately by the } \\
\text { operations team }\end{array}$ \\
\hline 2 & $\begin{array}{l}\text { Insignificant } \\
\text { effect }\end{array}$ & Can be handled with maintenance \\
\hline 3 & Minor effect & $\begin{array}{l}\text { Impaired performance of unfixed } \\
\text { components }\end{array}$ \\
\hline 4 & $\begin{array}{l}\text { Moderate } \\
\text { effect } 1\end{array}$ & $\begin{array}{l}\text { Component is not working but failure } \\
\text { does not result in SHUT DOWN of the } \\
\text { factory and its maintenance does not } \\
\text { require termination of machine } \\
\text { operation }\end{array}$ \\
\hline 5 & $\begin{array}{l}\text { Moderate } \\
\text { effect } 2\end{array}$ & $\begin{array}{l}\text { Components are not working and failure } \\
\text { does not result in SHUT DOWN of the } \\
\text { factory but its maintenance requires } \\
\text { termination of machine operation }\end{array}$ \\
\hline 6 & $\begin{array}{l}\text { Moderate } \\
\text { effect } 3\end{array}$ & $\begin{array}{l}\text { Components are not working and } \\
\text { failures resulting in SHUT DOWN of } \\
\text { the factory and their maintenance } \\
\text { requires termination of machine }\end{array}$ \\
\hline
\end{tabular}

Critical effect

Very critical effect 1

Very critical effect 2

10 operation less than 1 day

Components are not working and failures resulting in SHUT DOWN of the factory and their maintenance requires termination of machine operation more than 1 day

Components do not work and failures result in SHUT DOWN of the factory as well as interrupt overall system functionality

Components do not work and failure to result in BLACKOUT of the factory and process becomes collapse

Catostropic Failure of functions leads to property or effect accident damage to humans

Table 3. Data components, functions, and failure modes

\begin{tabular}{|c|c|c|c|c|}
\hline \multirow{2}{*}{ No } & \multirow{2}{*}{ Komponen } & \multirow{2}{*}{ Function } & \multicolumn{2}{|r|}{ Failure Mode } \\
\hline & & & Code & Deskripsi \\
\hline \multirow{3}{*}{1} & \multirow{3}{*}{ Strainer } & Filtering & 1.1 & Deterioration \\
\hline & & Fresh & & \\
\hline & & Water & 1.3 & $\begin{array}{l}\text { Clogging (High } \\
\text { differential pressure) }\end{array}$ \\
\hline \multirow{3}{*}{2} & \multirow{3}{*}{$\begin{array}{l}\text { Motor } \\
\text { Circulation } \\
\text { Pump } \\
\text { (Fresh } \\
\text { Water) }\end{array}$} & Fresh & 2.1 & Overload \\
\hline & & $\begin{array}{l}\text { Water } \\
\text { Pump }\end{array}$ & 2.2 & Vibration \\
\hline & & Drive & 2.3 & Overheating \\
\hline \multirow{3}{*}{3} & \multirow{3}{*}{$\begin{array}{l}\text { Sea Water } \\
\text { Motor } \\
\text { Pump }\end{array}$} & Sea & 3.1 & Overload \\
\hline & & $\begin{array}{l}\text { Water } \\
\text { Pump }\end{array}$ & 3.2 & Vibration \\
\hline & & Drive & 3.3 & Overheating \\
\hline \multirow[t]{3}{*}{4} & \multirow{3}{*}{$\begin{array}{l}\text { Fresh } \\
\text { Water } \\
\text { Circulation } \\
\text { Pump }\end{array}$} & $\begin{array}{l}\text { Pumping } \\
\text { Fresh }\end{array}$ & 4.1 & $\begin{array}{l}\text { Low fresh water } \\
\text { pressure on the pump } \\
\text { output side }\end{array}$ \\
\hline & & Water & 4.2 & Leakage \\
\hline & & & 4.3 & Vibration \\
\hline
\end{tabular}

Sea water pressure is

5.1 low on the pump output

5 Sea Water

$\begin{array}{ll}5 \text { Pump } & \text { Sea } \\ & \text { Water }\end{array}$

5.2 Leakage

$6 \quad$ Heat

cooling

\subsection{Vibration}

$6.1 \quad$ Leakage 


$\begin{array}{llll}\text { Exchanger } & \begin{array}{l}\text { Fresh } \\ \text { Water }\end{array} & 6.2 & \text { Low sea water flow } \\ & & 6.3 & \text { Low fresh water flow }\end{array}$

Table 4. The result of weighting failure mode based on the failure effect

\begin{tabular}{ccc}
\hline Code & Failure effect & $\mathrm{S}$ \\
\hline 1.1 & Contamination of dirt, clogged stream & 5 \\
& & \\
\hline 1.3 & Backflow on the cooling system & 4
\end{tabular}

1. Causes SHUT DOWN of the factory.

2.12 . Disrupt normal operation function (failure on cooling system)

\begin{tabular}{llc}
2.2 & Motor pump break / jam & 3 \\
\hline 2.3 & $\begin{array}{l}\text { 1. Causes SHUT DOWN of the factory. } \\
\text { 2. Disrupt normal operation function (failure on } \\
\text { cooling system) }\end{array}$ & 6
\end{tabular}

\begin{tabular}{llc}
\hline 3.1 & $\begin{array}{l}\text { 1. Causes SHUT DOWN of the factory. } \\
\text { 2. Disrupt normal operation function (failure of } \\
\text { lubrication and cooling system) }\end{array}$ & 5 \\
\hline 3.2 & Motor pump break / jam & 3 \\
\hline & 1. The risk of breaks on the pump motor. \\
3.3 & $\begin{array}{l}\text { 2. Causes SHUT DOWN of the factory. } \\
\text { 3. Disrupt normal operation function (failure on } \\
\text { cooling system) }\end{array}$
\end{tabular}

4.1 2. Disrupt normal operation function (failure on 5 cooling system)

1. Cause the volume of fresh water is reduced.

2.2 Disrupt normal operation function (failure on cooling system)

\begin{tabular}{llc}
\hline 4.3 & Motor pump break / jam & 3 \\
\hline 5.1 & $\begin{array}{l}\text { 1. Causes SHUT DOWN of the factory. } \\
\text { 2. Disrupt normal operation function (failure on } \\
\text { cooling system) }\end{array}$ & 5 \\
\hline & $\begin{array}{l}\text { 1. Cause the volume of sea water is reduced. } \\
5.2\end{array}$ & $\begin{array}{l}\text { 2. Disrupt normal operation function (failure on } \\
\text { cooling system) }\end{array}$ \\
\hline 5.3 & Motor pump break / jam \\
\hline 6.1 & 1. Temperature exchange is not optimal. \\
\hline & 2. The amount of fresh water and sea water is not \\
\hline
\end{tabular}

\begin{tabular}{l}
\hline in accordance with the limits that should be. \\
3. Maintenance of monitoring and control support \\
equipment is not possible. \\
$\begin{array}{l}\text { 1. Cause the volume of sea water is reduced. } \\
6.2 \text { 2. Disrupt normal operation function (failure on } \\
\text { cooling system) }\end{array}$ \\
$\begin{array}{l}\text { 1. Cause the volume of sea water is reduced. } \\
\text { 2. Disrupt normal operation function (failure on } \\
\text { cooling system) }\end{array}$ \\
\hline
\end{tabular}

\subsubsection{Determination of weight criteria of Total RPN.}

The determination of the total RPN range is done by finding the relationship between $\mathrm{S}$ and $\mathrm{O}$ parameters based on their respective levels and quality weights. The results are shown in Table 5. From Table 5 can be obtained:
a). Minor RPN : $1-20$
b). Moderate RPN : $21-28$
c). Major RPN : $30-80$

Table 5. The result of the weight criteria of Total RPN

\begin{tabular}{|c|c|c|c|c|c|c|c|c|c|c|c|}
\hline & \multicolumn{10}{|c|}{$S$} \\
\hline & & 1 & 2 & 3 & 4 & $j$ & 6 & 7 & 8 & 9 & 10 \\
\hline \multirow{8}{*}{0} & 1 & 1 & 2 & 3 & 4 & $j$ & 6 & 1 & 8 & 9 & 10 \\
\hline & 2 & 2 & 4 & 6 & 8 & 10 & 12 & 14 & 16 & 18 & 20 \\
\hline & 3 & 3 & 6 & 9 & 12 & 15 & 18 & 21 & 24 & 27 & 30 \\
\hline & 4 & 4 & 8 & 12 & 16 & 20 & 24 & 28 & 32 & 36 & 40 \\
\hline & $j$ & $j$ & 10 & 15 & 20 & 25 & 30 & 35 & 40 & 45 & 50 \\
\hline & 6 & 6 & 12 & 18 & 24 & 30 & 36 & 42. & 48 & 54 & 60 \\
\hline & 1 & 1 & 14 & 21 & 28 & 35 & 42. & 49 & 56 & 63 & 70 \\
\hline & 8 & 8 & 16 & 24 & 32 & 40 & 48 & 56 & 64 & 72 & 80 \\
\hline
\end{tabular}

\section{2..1.3 Determination of maintenance action.}

The maintenance actions performed are related to the quality weights of the total RPN for each machine. Maintenance actions carried out are:

1. Simple Inspection (SI) or Routine Inspection $(R I)$ is maintenance action with activity in the form of inspection, cleaning, lubrication, examination, running test, function test and other light maintenance activities. SI performed for the incident of failure per month into the RPN minor category.

2. Mean Inspection (MI) is maintenance action with activity equal to SI added with replacement activity, repair of damaged / worn components. MI performed for the occurrence of failure per month in the category of moderate RPN.

\subsection{Adaptive Neural Network}

ANN (Artificial Neural Network) is a composition of a number of simple elements that operate in parallel. ANN is trained in such a way as to produce outputs that approach a

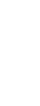


particular output target based on a particular input pattern. Back Propagation (BP) is a generalization of the WidrowHoff learning rule where the term back-propagation refers to how gradient error is calculated for nonlinear multilayer networks. ANN-BP uses the FFNN (Feed Forward NN) architecture as shown in Figure 1

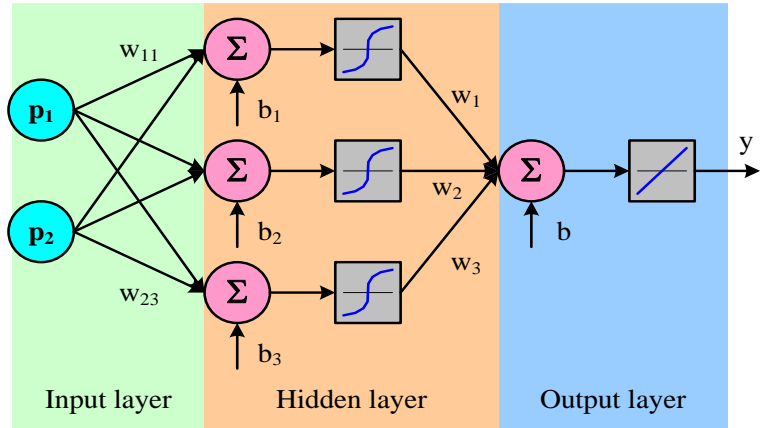

(a)

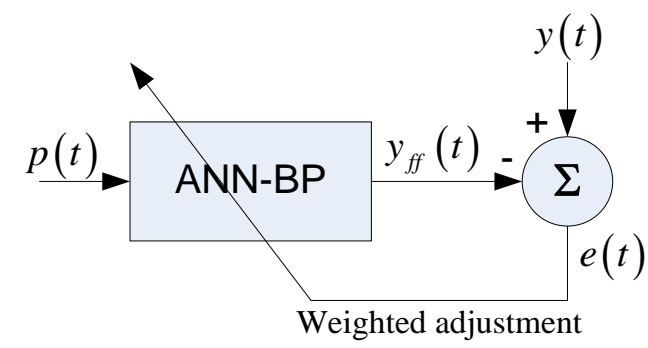

(b)

Figure 1. (a). FFNN architecture; (b). ANN-BP

ANN-BP is not always able to achieve the target error that has been set. This can be caused by various things, one of which is the pattern of training data used. In this case, it is required a method that can force ANN-BP to reach the target error without having to analyze the pattern of training data first. Adaptive ANN-BP applies adaptive learning methods in performing weighted fixes for each layer. Weighing each layer is randomly selected and then updated using a very small random number. An Adaptive ANN-BP training model is shown in Figure 2. The ANN-BP Adaptive Learning Algorithm is shown in Figure 3

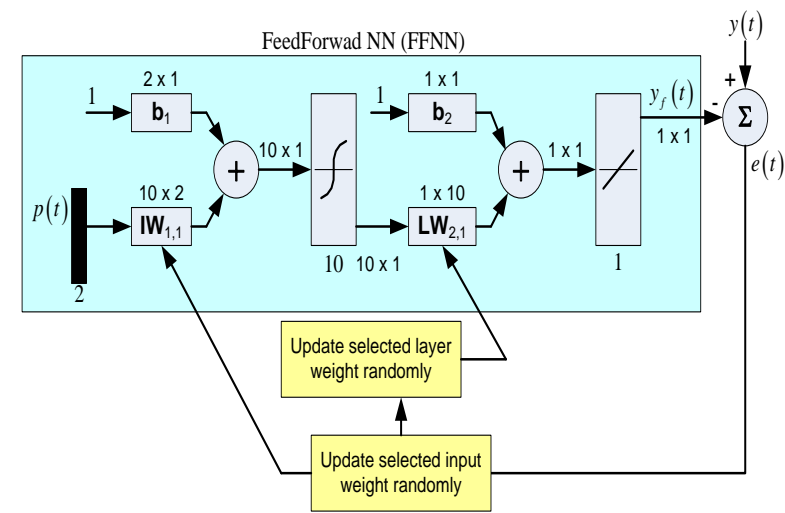

Figure 2. Adaptive learning model of ANN-BP

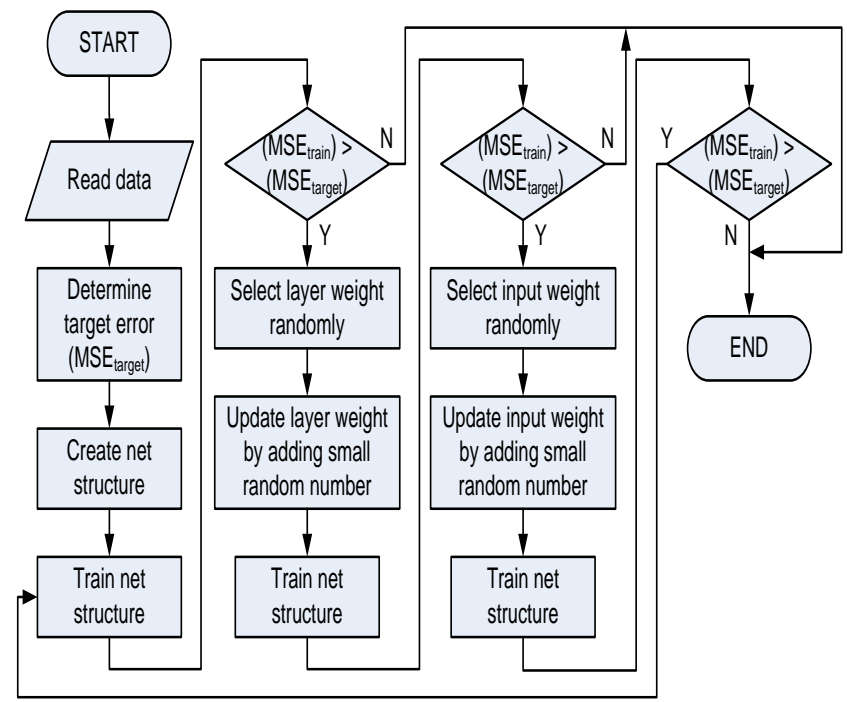

Figure 3. The algorithm of adaptive learning model of ANN-BP

\section{RESULTS AND DISCUSSION}

\subsection{Historical data of cooling system failure}

The historical data of cooling system failure is taken at the operating interval of 2011 - 2016. The cooling system has 6 components with 17 failure modes. Each failure mode is assumed to have the same contribution to the failure of the cooling system. Because the recondition (overhaul) is performed on average every 18 months, it is assumed that one period has a span of 18 months. The average yield of the number of failure per month is shown in Table 6. Based on Table 5, the RPN calculation results are shown in Table 7.

Table 6. The historical data of cooling system failure in period 2011-2016

\begin{tabular}{lllllllllllllllllll}
\hline Peniod & 1 & 2 & 3 & 4 & 5 & 6 & 7 & 8 & 9 & 10 & 11 & 12 & 13 & 14 & 15 & 16 & 17 & 18 \\
\hline 1 & 3 & 1 & 3 & 4 & 5 & 5 & 6 & 6 & 4 & 2 & 8 & 6 & 5 & 5 & 6 & 7 & 3 & 8 \\
2 & 2 & 1 & 2 & 4 & 5 & 1 & 1 & 8 & 1 & 1 & 5 & 5 & 1 & 4 & 5 & 8 & 2 & 8 \\
3 & 3 & 3 & 2 & 6 & 6 & 1 & 2 & 9 & 2 & 2 & 8 & 5 & 2 & 5 & 6 & 9 & 3 & 9 \\
4 & 2 & 4 & 2 & 9 & 8 & 1 & 3 & 9 & 3 & 3 & 7 & 7 & 2 & 6 & 7 & 9 & 6 & 9 \\
\hline
\end{tabular}

Table 7. The RPN calculation results in Period 1 - 4

\begin{tabular}{ccccccccccccccccccc}
\hline & \multicolumn{11}{c}{ Peniod } & 1 & 1 & 10 & 10 & 10 \\
& 1 & 2 & 3 & 4 & 5 & 6 & 7 & 8 & 9 & 10 & 11 & 12 & 13 & 14 & 15 & 16 & 17 & 18 \\
\hline 1 & 12 & 6 & 15 & 17 & 24 & 23 & 30 & 24 & 22 & 9 & 36 & 29 & 23 & 28 & 30 & 32 & 15 & 37 \\
2 & 9 & 5 & 11 & 20 & 23 & 3 & 3 & 23 & 6 & 6 & 23 & 26 & 5 & 22 & 25 & 37 & 12 & 36 \\
3 & 12 & 14 & 12 & 31 & 28 & 5 & 8 & 38 & 9 & 11 & 40 & 26 & 11 & 25 & 28 & 43 & 18 & 45 \\
4 & 9 & 20 & 8 & 41 & 40 & 4 & 11 & 39 & 15 & 13 & 35 & 33 & 10 & 27 & 31 & 39 & 29 & 43 \\
\hline
\end{tabular}

FFNN training performance function is using MSE (Mean Square Error) expressed by: 


$$
M S E=\frac{1}{N} \sum_{i=1}^{N}\left(y(i)-y_{f f}(i)\right)^{2}
$$

Where $y(i), y_{f f}(i)$, and $N$ are target output, FFNN output, and the number of training data, respectively. Because the processed RPN data are in the period 20112016 then there will be: $6 \times 12=72$ data. The data in operation period 1-3 is used as training data, while the data in operation period 4 is used as test data. The FFNN architecture uses a hidden neuron of 15 neurons with target error $(\mathrm{MSE})=0.5$. By using the programming tool MATLAB obtained the results as shown in Figure 4. The MAE of training result is 0.333 (meet below target error). Validation of trained net structures using RPN data for the operation period 4 is shown in Figure 5.

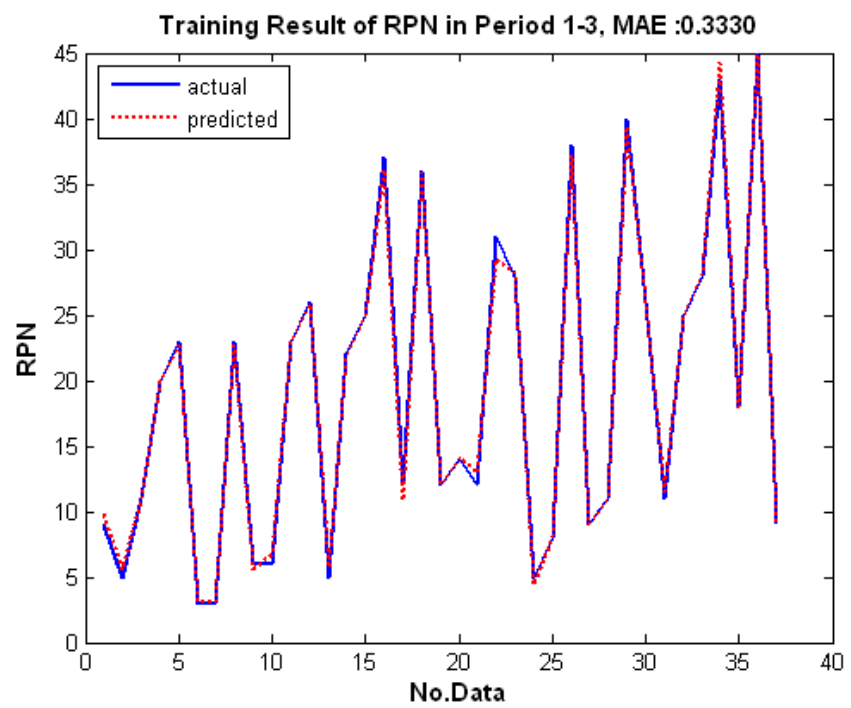

Figure 4. Training result

Validation result using data in period 4 $\mathrm{MAE}=3.0000$

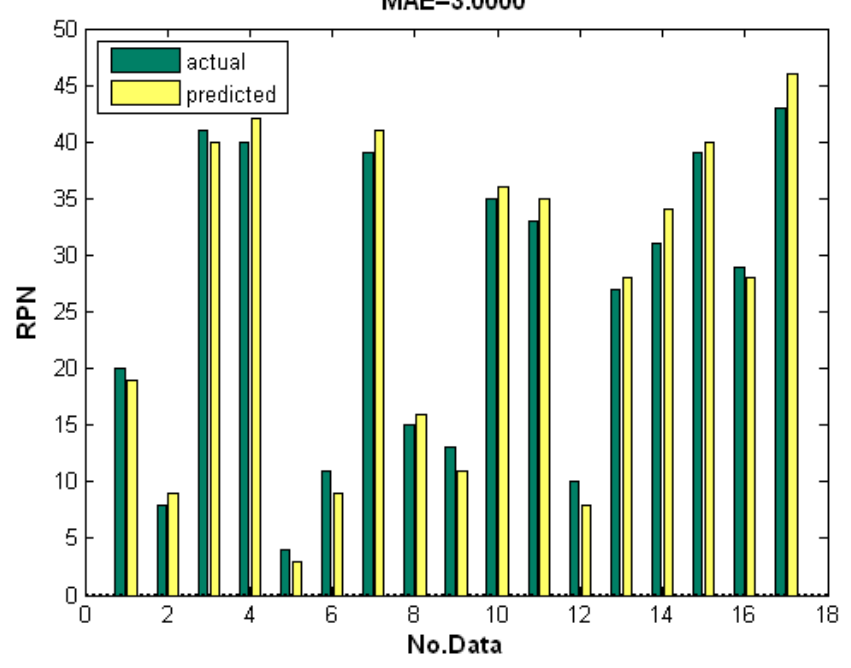

Figure 5. Validation result

From Figure 5 it can be concluded that the test result using RPN operation period 4 resulted in a MAE of 3. This prediction error is still acceptable because it can be considered the same as the occurrence of 1 (one) failure with RPN Minor weights. The predicted results of the RPN for the operation period 5 (2017/2018) are shown in Figure predictions with reference to the RPN criteria weights as in 6. Maintenance actions are planned based on RPN

Table 5 and the corresponding types of maintenance actions. Action maintenance was done one month before as anticipatory action. The results of the maintenance scheduling are shown in Table 7.

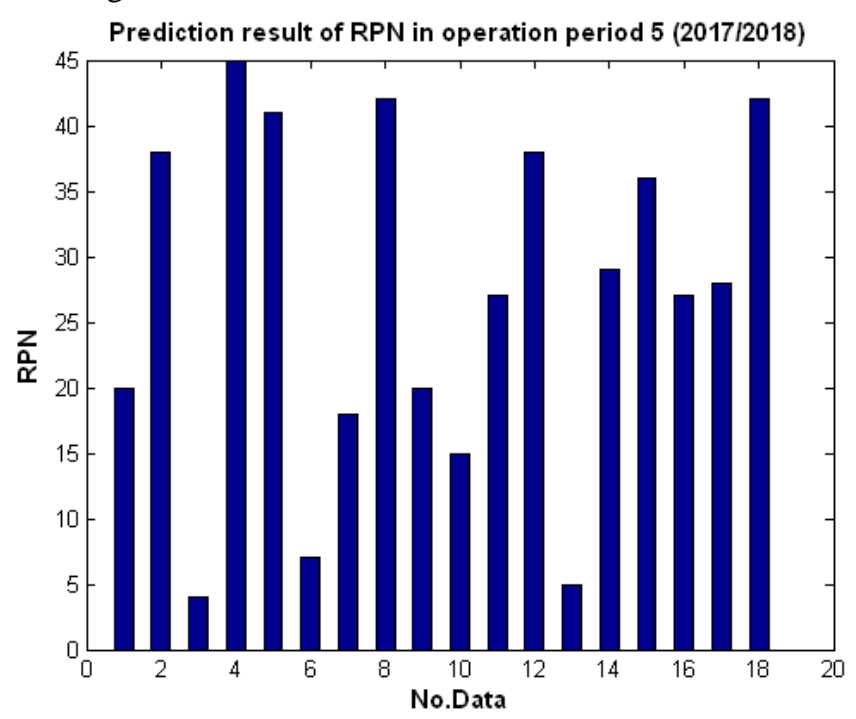

Figure 6. Prediction result of RPN in operation period 5

Table 7. The result of Maintenance Scheduling in operation period 5

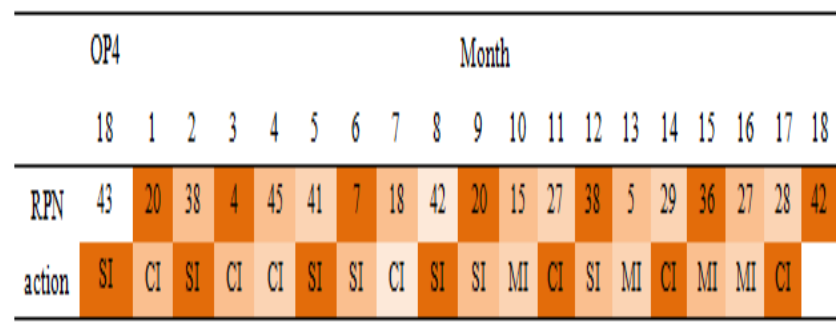

\section{CONCLUSION}

This study has implemented adaptive ANN-BP to predict RPN in the next operating period based on RPN in several previous operating periods. The result of testing the trained net structure using RPN in operation period 4 resulted in $\mathrm{MSE}=3$. This prediction error is still acceptable because it can be considered the same as the occurrence of one failure with RPN Minor weights. The predicted RPN for the operation period 5 is then used to determine maintenance actions (SI, MI, CI) based on the weight of the RPN criteria. Maintenance actions performed one month before to anticipate the occurrence of failure based on predicted results. Future work is how to improve prediction results using ANN-BP adaptive, including validation techniques for actual conditions.

\section{ACKNOWLEDGMENTS}

The authors would like to express their heartfelt thanks to The Modern Computing Research Center, Department of Information Technology, State Polytechnic of Samarinda for providing all their support.
\& Sciences Publication

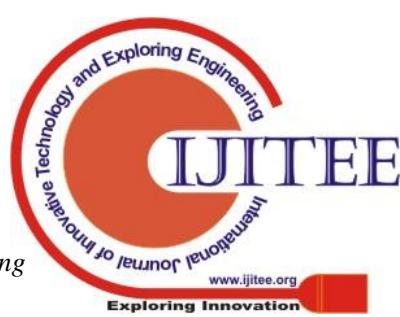




\section{REFERENCES}

1. G. P. Sullivan, R. Pugh, A. P. Melendez, and W. D. Hunt. (2010). Operations \& Maintenance Release 3.0: Operations \& Maintenance - Best Practices.

2. F. S. Dhillon, "EFECT OF PREVENTIVE MAINTENANCE IN INDUSTRIES," International Journal In Applied Studies And Production Management, vol. 2, pp. 63-68, 2016

3. L. Topliceanu, P. Gabriel, and I. Furdu, "Functional Problems and Maintenance Operations of Hydraulic Turbines," TEM JOURNAL - Technology, Education, Management, Informatics, vol. 5, pp. 32-37, 2016.

4. N. Pancholi and M.G.Bhatt, "Performance Reliability Improvement by Optimizing Maintenance Practices through Failure Analysis in Process Industry -A Comprehensive Literature Review," IOSR Journal of Mechanical and Civil Engineering (IOSR-JMCE), vol. 13, pp. 66-73, 2016.

5. D. Isaacs, A. Astarola, J. Diaz, and B. Arejita, "Making Factories Smarter Through Machine Learning," IIC Journal of Innovation 2017.

6. S. Munirathinam and B. Ramadoss, "Predictive Models for Equipment Fault Detection in the Semiconductor Manufacturing Process," International Journal of Engineering and Technology, vol. 8, pp. 273-285, 2016.

7. H. Wang, X. Ye, and M. Yin, "Study on Predictive Maintenance Strategy," International Journal of u- and eService, Science and Technology, vol. 9, pp. 295-300, 2016.

8. A. P. Rifai, H.-T. Nguyen, and S. Z. M. Dawal, "Multiobjective adaptive large neighborhood search for distributed reentrant permutation flow shop scheduling," Applied Soft Computing, vol. 40, pp. 42-57, 2016.

9. N. Banduka, I. Veža, and B. Bilić, "An integrated lean approach to Process Failure Mode and Effect Analysis (PFMEA): A case study from automotive industry," Advances in Production Engineering \& Management, vol. 11 , pp. $355-365,2016$.

10. M. A. Geetha and R. S. P. Kumar, "Effective Estimation of Total Failure Mode Effects and Analysis in Tea Industry," Asian Journal of Information Technology, vol. 15, pp. 4030-4039, 2016.

11. X. Deng and W. Jiang, "Fuzzy Risk Evaluation in Failure Mode and Effects Analysis Using a D Numbers Based Multi-Sensor Information Fusion Method," Sensors, vol. 17, p. 2086, 2017.

12. M. S. Upadhya, "Fuzzy Logic-Based Failure Mode Effect and Criticality Analysis -A Case Study of Water Filters of a Company," Journal of Computer Applications (JCA), vol. 6, pp. 89-93, 2013.

13. D. Zhou, Y. Tang, and W. Jiang, "A Modified Model of Failure Mode and Effects Analysis Based on Generalized Evidence Theory," Mathematical Problems in Engineering, vol. 2016, pp. 1-11, 2016.

14. A. .R, Priyanka, and R. M. .Patil, "Health Monitoring In Aerospace System," International Journal of Informative \& Futuristic Research vol. 4, pp. 7556-7561, 2017.

15. L. Zhang, "Big Data Analytics for Fault Detection and its Application in Maintenance - Doctoral Thesis," Doctoral, Department of Operation and Maintenance Engineering, University of Technology, Lulea- Sweden, 2016.

16. S. M. Rezvanizaniani, J. Dempsey, and J. Lee, "An Effective Predictive Maintenance Approach based on Historical Maintenance Data using a Probabilistic Risk Assessment: PHM14 Data Challenge," International Journal of Prognostics and Health Management, pp. 1-13, 2014.

17. G. Li, X. Wang, A. Yang, M. Rong, and K. Yang, "Failure Prognosis of High Voltage Circuit Breakers with Temporal Latent Dirichlet Allocation," Energies, vol. 10, p. 1913, 2017.
18. P. Pillai, A. Kaushik, S. Bhavikatti, A. Roy4, and V. Kumar, "A Hybrid Approach for Fusing Physics and Data for Failure Prediction," International Journal of Prognostics and Health Management, 2016. 